\title{
Blinding Schema Code
}

National Cancer Institute

\section{Source}

National Cancer Institute. Blinding Schema Code. NCI Thesaurus. Code C93520.

A coded value specifying the type of blinding that is used for the trial. 